\title{
The Current Status of Immune Checkpoint Inhibitors in Neuro-Oncology: A Systematic Review
}

\author{
Cyrillo G. Brahm ${ }^{1,2}$, Myra E. van Linde ${ }^{2}$, Roelien H. Enting ${ }^{3}$, Maaike Schuur ${ }^{4}$ (D), \\ René H.J. Otten ${ }^{5} \mathbb{D}$, Martijn W. Heymans ${ }^{6}\left(\mathbb{D}\right.$, Henk M.W. Verheul ${ }^{2,7} \mathbb{D}$ and \\ Annemiek M.E. Walenkamp ${ }^{1, *}$
}

1 Department of Medical Oncology, University of Groningen, University Medical Center Groningen, 9700 RB Groningen, The Netherlands; c.brahm@amsterdamumc.nl

2 Department of Medical Oncology, Cancer Center Amsterdam, Amsterdam University Medical Centers, location VUmc, 1007 MB Amsterdam, The Netherlands; m.vanlinde@amsterdamumc.nl (M.E.v.L.); henk.verheul@radboudumc.nl (H.M.W.V.)

3 Department of Neurology, University of Groningen, University Medical Center Groningen, 9700 RB Groningen, The Netherlands; r.h.enting@umcg.nl

4 Department of Neurology, Cancer Center Amsterdam, Amsterdam University Medical Centers, location VUmc, 1007 MB Amsterdam, The Netherlands; m.schuur@amsterdamumc.nl

5 University Library, Vrije Universiteit Amsterdam, 1007 MB Amsterdam, The Netherlands; r.otten@vu.nl

6 Department of Epidemiology and Biostatistics, Amsterdam University Medical Centers, location VUmc, 1007 MB Amsterdam, The Netherlands; mw.heymans@amsterdamumc.nl

7 Department of Medical Oncology, Radboud University Medical Center, 6500 HB Nijmegen, The Netherlands

* Correspondence: a.walenkamp@umcg.nl; Tel.: +31-50-3612821; Fax: +31-50-3614862

Received: 13 February 2020; Accepted: 2 March 2020; Published: 4 March 2020

check for updates

\begin{abstract}
The introduction of immune checkpoint inhibitors (ICI), as a novel treatment modality, has transformed the field of oncology with unprecedented successes. However, the efficacy of ICI for patients with glioblastoma or brain metastases (BMs) from any tumor type is under debate. Therefore, we systematically reviewed current literature on the use of ICI in patients with glioblastoma and BMs. Prospective and retrospective studies evaluating the efficacy and survival outcomes of ICI in patients with glioblastoma or BMs, and published between 2006 and November 2019, were considered. A total of 88 studies were identified ( $n=8$ in glioblastoma and $n=80$ in BMs). In glioblastoma, median progression-free (PFS) and overall survival (OS) of all studies were 2.1 and 7.3 months, respectively. In patients with BMs, intracranial responses have been reported in studies with melanoma and non-small-cell lung cancer (NSCLC). The median intracranial and total PFS in these studies were 2.7 and 3.0 months, respectively. The median OS in all studies for patients with brain BMs was 8.0 months. To date, ICI demonstrate limited efficacy in patients with glioblastoma or BMs. Future research should focus on increasing the local and systemic immunological responses in these patients.
\end{abstract}

Keywords: Immune checkpoint inhibitors; glioblastoma; brain metastases; brain tumor; systematic review

\section{Introduction}

Treating patients with primary brain tumors and brain metastases can be challenging. This is primarily due to the poor prognosis of these patients despite maximal treatment and the presence of the blood-brain barrier, posing an obstacle to overcome for most systemic treatments [1]. Glioblastoma is the most common and most aggressive primary brain tumor in adults, accounting for more than $50 \%$ of all gliomas. Currently, first-line standard treatment for patients with glioblastoma consists of maximal 
resection, followed by postoperative radiotherapy (RT) with concomitant and adjuvant temozolomide (TMZ) chemotherapy [2]. Since the addition of TMZ to postoperative treatment, two-year and five-year survival have improved to $27 \%$ and $10 \%$, respectively [3]. Furthermore, the addition of tumor-treating fields, an anti-mitotic treatment modality, to TMZ maintenance therapy demonstrated a statistically significant improvement in progression-free and overall survival, compared to TMZ maintenance therapy alone (6.7 months vs. 4.0 months and 20.9 months vs. 16.0 months, respectively) [4]. However, recurrence is almost inevitable and therefore, the prognosis for these patients remains poor with a median survival of only 12-15 months [3]. At the time of recurrence, options are limited due to the distinct limitations in the use of surgery and re-irradiation, and the poor treatment response to chemotherapy and targeted therapy [5-7].

Brain metastases (BMs) occur in $8-10 \%$ of all cancer patients as an unfortunate complication of systemic dissemination [8,9]. The cumulative incidence of brain metastases is highest in melanoma ( $28 \%)$, followed by lung cancer $(27 \%)$, renal cell cancer $(11 \%)$, breast cancer $(8 \%)$, and testicular cancer (8\%) [10]. Similar to glioblastoma, most patients with brain metastases have a dismal prognosis of 12-15 months despite multidisciplinary treatment with surgery, irradiation and/or systemic treatment [11]. Therefore, there is an unmet need for more effective treatments for patients with glioblastoma or brain metastases.

Over the past few decades, significant progress has been made in the understanding of how cancer cells are able to evade the immune system through the expression of immune checkpoints that suppress $\mathrm{T}$ cell function and proliferation. Currently, the clinically most relevant immune checkpoints are the cytotoxic $\mathrm{T}$ lymphocyte antigen 4 (CTLA-4), the programmed death 1 receptor (PD-1) and its ligand (PD-L1) [12,13]. Interestingly, blockade of these immune checkpoints with antibodies, such as ipilimumab (anti-CTLA-4), nivolumab (anti-PD-1), and pembrolizumab (anti-PD-1), successfully demonstrated efficacy in various solid tumors, predominantly melanoma and non-small cell lung cancer (NSCLC), and prolonged the survival of patients with extracranial disease [14-16].

The introduction of immune checkpoint inhibitors (ICI), as an unprecedented treatment modality, has consequences for clinical decision making of neuro-oncologists and treatment recommendations of Neuro-Oncology tumor boards. Furthermore, these treatment recommendations and decisions may differ per tumor type. Therefore, we systematically reviewed and summarized current literature on the use of checkpoint inhibitors in patients with glioblastoma and brain metastases to support neuro-oncologists and neuro-oncology tumor boards in their clinical decision making and treatment recommendations.

\section{Methods}

\subsection{Literature Search}

The systematic review followed the guidelines of the Preferred Reporting Items for Systematic Reviews and Meta-Analysis (PRISMA)-statement (http://www.prisma-statement.org). PubMed, EMBASE.com and the Cochrane Library (via Wiley) were searched for potentially eligible publications from inception (by C.B. and R.O.) up to 11 November 2019. The following keywords (including synonyms and closely related words) were used as index terms or free-text words: 'glioblastoma OR $\mathrm{gbm}^{\prime}$ or 'brain metastases OR central nervous system metastases' and 'immunotherapy OR immune checkpoint inhibitor'. A full overview of the complete search strategies can be found in supplementary Table S1. Subsequently, the titles and abstracts found by the database searches were exported to a reference manager database to remove all duplicate articles.

\subsection{Study Selection}

Eligible studies included (i) prospective or retrospective studies in patients with glioblastoma or brain metastases, (ii) reporting on the efficacy and survival outcomes after treatment with immune checkpoint inhibitors and (iii) were published in English between January 2006 and the end of 
November 2019. Case reports, scientific abstracts or studies with $<10$ patients were excluded. In the first selection phase, two authors (C.B. and M.L.) independently screened and reviewed the titles and abstracts of all identified articles.

\subsection{Data Extraction and Statistical Analysis}

The two reviewers (C.B. and M.L.) extracted the following data from each article: author (year), study design, tumor type, therapeutic agent and dose, type of radiation therapy, number of participants, objective response rate (ORR), local brain metastasis control rate at 6 and 12 months, distant brain metastasis control rate at 6 and 12 months, progression-free survival (PFS), and overall survival (OS). If criteria other than RANO or RECIST were used, these were taken into consideration for calculating the ORR. In case ORR was not reported in an article, it was calculated from raw proportions of events (complete response (CR), partial response (PR), or stable disease (SD) divided by the total number of evaluable patients. Descriptive analyses were performed to assess outcomes and demographic characteristics. Freeman-Tukey double arcsine transformation of proportions was applied before pooling these values and results were back transformed. A random effects model was used for all pooled proportions. Forest plots were generated to show the prevalence of each study and the overall pooled prevalence and $\mathrm{I}^{2}$ statistics were calculated. R software version 3.6.1 (package meta) was used to perform meta-analyses.

\section{Results}

\subsection{Literature Search Results}

A flow diagram of the literature search, review and selection process is illustrated in Figure 1. In total, the literature search yielded 10,675 individual records, after removal of duplicate records. Screening of the titles and abstracts of these records resulted in 206 records eligible for full-text assessment. Finally, 118 records were excluded after reading the full text, resulting in 88 eligible publications for this review.

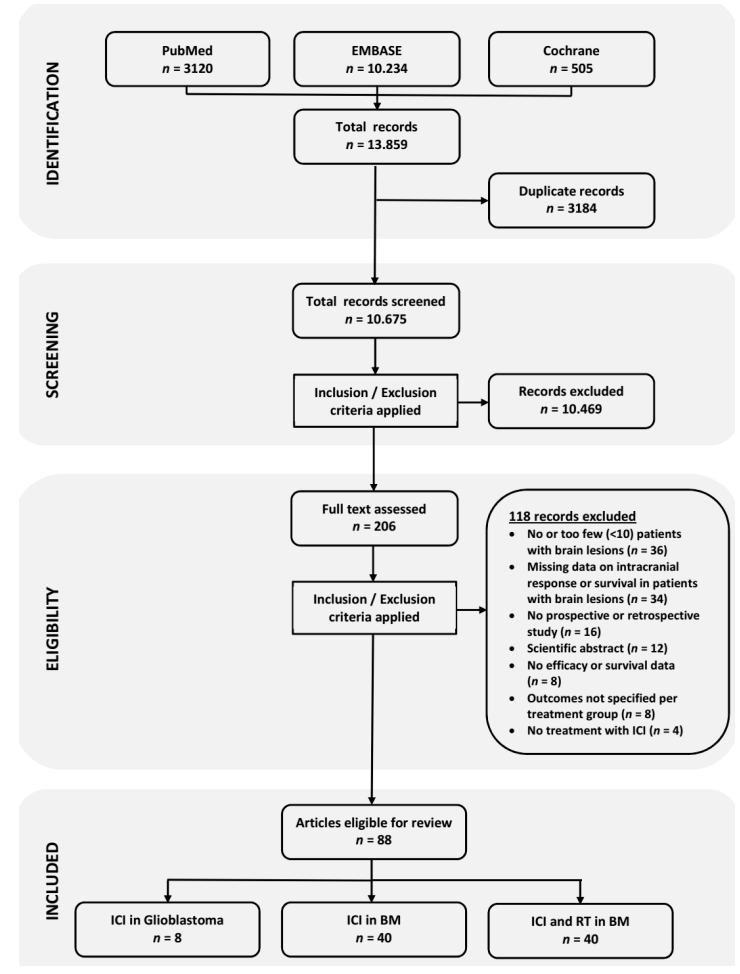

Figure 1. Flow diagram illustrating the literature search and study selection. 


\subsection{Overview of the Studies}

For glioblastoma, a total of 8 studies were included in this systematic review, including two phase I trials [17,18], two phase II trials [19,20] and four retrospective analyses [21-24] (Table 1). In two studies, pembrolizumab was administered in patients with recurrent glioblastoma every three weeks (Q3W) in varying doses [19,22]. Three studies used nivolumab, administered most frequently in a dose of $3 \mathrm{mg} / \mathrm{kg}$ every two weeks (Q2W) [17,23,24]. Ipilimumab was only used in combination with bevacizumab [21] or nivolumab [17]. Lastly, one study used the PD-L1 inhibitor atezolizumab, administered $1200 \mathrm{mg}$ Q3W [18].

For brain metastases, 40 studies assessed the efficacy of ICI without RT [25-64] and 40 studies explored the combination of ICI and RT (Table 2; Tables S2-S4). The 41 studies with ICI in BMs include three phase III trials, eleven phase II trials, ten Extended Access Program (EAP) studies and 17 retrospective analyses. Aside from one phase I trial, all of the other studies with ICI and RT in BMs were retrospective analyses with a highly heterogeneous study design. Therefore, the outcomes of studies with ICI and RT are reported separately in the supplementary data (Tables S3 and S4). The most common tumor types in all studies of ICI with or without RT were melanoma and NSCLC. 
Table 1. Primary outcomes of clinical studies with immune checkpoint inhibitors in patients with glioblastoma.

\begin{tabular}{|c|c|c|c|c|c|c|c|c|}
\hline Author & Study Design & Tumor Type & Setting & Agent & No. of Patients & ORR & PFS & OS \\
\hline & & & & & & $\%$ & Months & Months \\
\hline Carter (2016) [21] & Retrospective & Glioblastoma & Recurrent & $\mathrm{IPI}+\mathrm{BEV}$ & 16 & 31.0 & N.A. & N.A. \\
\hline Blumenthal (2016) [22] & Retrospective & Glioma & Recurrent & PEMBRO & 17 (10 GBM) & 0.0 & N.A. & 2.6 [range $0.4-11.6$ ] \\
\hline Chamberlain (2017) [23] & Retrospective & Glioblastoma & Recurrent & NIVO & 16 & 0.0 & $2.0(95 \%$ CI $1.3-2.7)$ & $3.5(95 \%$ CI $2.8-4.2)$ \\
\hline Omuro (2018) Cohort A [17] & I & Glioblastoma & Recurrent & NIVO & 10 & 11.0 & $1.9(95 \%$ CI 1.3-4.6) & 10.4 (95\% CI $4.1-22.8)$ \\
\hline Omuro (2018) Cohort B & I & Glioblastoma & Recurrent & $\mathrm{NIVO}+\mathrm{IPI}$ & 10 & 0.0 & $1.5(95 \%$ CI $0.5-2.8)$ & $9.2(95 \%$ CI $3.9-12.7)$ \\
\hline Omuro (2018) Cohort C & I & Glioblastoma & Recurrent & $\mathrm{NIVO}+\mathrm{IPI}$ & 20 & 10.0 & $2.1(95 \%$ CI $1.4-2.8)$ & $7.3(95 \%$ CI $4.7-12.9)$ \\
\hline Mantica (2018) [24] & Retrospective & Glioblastoma & Recurrent & NIVO (+ BEV) & 37 & 0.0 & 4.6 [range 0.5-15.0] & 6.5 [range 0.8-19.5] \\
\hline Lukas (2018) [18] & I & Glioblastoma & Recurrent & ATEZO & 16 & 6.0 & 1.2 [range $0.7-10.7$ ] & 4.2 [range 1.2-18.8+] \\
\hline Cloughesy (2019) Cohort A [19] & II & Glioblastoma & Recurrent & PEMBRO & 16 & N.A. & 3.3 & 13.7 \\
\hline Cloughesy (2019) Cohort B [19] & II & Glioblastoma & Recurrent & PEMBRO & 16 & N.A. & 2.4 & 7.5 \\
\hline Schalper (2019) [20] & II & Glioblastoma & Newly diagnosed and Recurrent & NIVO & 29 & N.A. & $4.1(95 \%$ CI $2.8-5.5)$ & $7.3(95 \%$ CI 5.4-7.9) \\
\hline
\end{tabular}

ATEZO Atezolizumab; BEV Bevacizumab; ICI Immune checkpoint inhibitor; IPI Ipilimumab; N.A. Not available; NIVO Nivolumab; PEMBRO Pembrolizumab. 
Table 2. Primary outcomes of clinical studies with immune checkpoint inhibitors in patients with brain metastases.

\begin{tabular}{|c|c|c|c|c|c|c|c|}
\hline Author & Study Design & Tumor Type & Agent & No. of Patients & ORR & PFS & OS \\
\hline & & & & & $\%$ & Months & Months \\
\hline Altomonte (2013) [25] & EAP (Retrospective) & Melanoma & IPI & 11 & 0 & $3.0(95 \%$ CI 2.4-3.6) & $4.0(95 \%$ CI 2.4-5.6) \\
\hline Berrocal (2014) [26] & EAP (Retrospective) & Melanoma & IPI & 29 & 10.8 & N.A. & $3.9(95 \%$ CI 1.1-6.8) \\
\hline Chasset (2015) [28] & EAP (Retrospective) & Melanoma & IPI & 23 & 17 & N.A. & $7.0(95 \%$ CI $4.0-12.0)$ \\
\hline Di Giacomo (2012)(2014) [30,31] & II & Melanoma & IPI + Fotemustine & 20 & 40.0 & $3.0+(95 \%$ CI $2.9-3.1)$ & $12.7(95 \%$ CI $2.7-22.7)$ \\
\hline Goldberg (2016) [36] & II & Melanoma & PEMBRO & 18 & $22.0 *(95 \%$ CI $7.0-48.0)$ & N.A. & N.R. \\
\hline González-Cao (2017) [37] & EAP (Retrospective) & Melanoma & PEMBRO & 10 & $40.0^{*}$ & N.A. & N.A. \\
\hline Kluger (2019) [38] & II & Melanoma & PEMBRO & 23 & $26.0 *(95 \%$ CI $10.0-48.0)$ & 2.0 (95\% CI, 2.0-N.R.) & 17.0 (95\% CI 10.0-N.R.) \\
\hline Konstantinou (2014) [39] & EAP (Retrospective) & Melanoma & IPI & 38 & $5.3^{*}$ & N.A. & 3.3 \\
\hline Long (2018) Cohort A [40] & II & Melanoma & $\mathrm{NIVO}+\mathrm{IPI}$ & 35 & $46.0 *(95 \%$ CI $29.0-63.0)$ & N.R. † (95\% CI 2.9-N.R) & N.R. (95\% CI 8.5-N.R.) \\
\hline Long (2018) Cohort B [40] & II & Melanoma & NIVO & 25 & $20.0 *(95 \%$ CI $7.0-41.0)$ & $2.5+(95 \%$ CI $1.7-2.8)$ & 18.5 (95\% CI 6.9-N.R.) \\
\hline Long (2018) Cohort C [40] & II & Melanoma & NIVO & 16 & $6.0 *(95 \%$ CI $0.0-30.0)$ & $2.3+(95 \%$ CI $1.4-4.3)$ & 5.1 (95\% CI 1.8-N.R.) \\
\hline Margolin (2012) Cohort A [41] & II & Melanoma & IPI & 51 & $16.0 *(95 \%$ CI 7.0-29.0) & $1.5+(95 \%$ CI $1.2-2.5)$ & 7.0 (95\% CI 4.1-10.8) \\
\hline Margolin (2012) Cohort B [41] & II & Melanoma & IPI & 21 & $5.0 *(95 \%$ CI $0.1-24.0)$ & $1.2+(95 \%$ CI $1.2-1.3)$ & 3.7 (95\% CI 1.6-7.3) \\
\hline Parakh (2017) [43] & Retrospective & Melanoma & NIVO or PEMBRO & 66 & $21.0^{*}$ & $5.3+(95 \%$ CI 3.3-8.2) & 9.9 (95\% CI 6.9-17.7) \\
\hline Parakh (2019) [42] & Retrospective & Melanoma & $\mathrm{NIVO}+\mathrm{IPI}$ & 11 & $18.0^{*}$ & $2.9(95 \%$ CI $0.6-7.1)$ & 17.4 (95\% CI 7.1-N.R.) \\
\hline Queirolo (2014) [44] & EAP (Retrospective) & Melanoma & IPI & 145 & 12.0 & $3.1(95 \%$ CI $2.7-3.5)$ & $4.3(95 \%$ CI $3.4-5.2)$ \\
\hline Tawbi (2018) [47] & II & Melanoma & $\mathrm{NIVO}+\mathrm{IPI}$ & 94 & $55.0 *(95 \%$ CI $45-66)$ & N.R. & N.R. \\
\hline Weber (2011) [46] & II & Melanoma & IPI (+ Budesonide) & 12 & 16.7 & N.A. & 14.0 \\
\hline Bjørnhart (2019) [27] & Retrospective & NSCLC & NIVO or PEMBRO & 21 & $4.8^{*}$ & $4.2(95 \%$ CI $2.5-5.9)$ & $8.2(95 \%$ CI $1.0-15.5)$ \\
\hline Crinò (2019) [29] & EAP & NSCLC & NIVO & 409 & 17.0 & $3.0(95 \%$ CI $2.7-3.3)$ & 8.6 (95\% CI 6.4-10.8) \\
\hline Dumenil (2018) [32] & Retrospective & NSCLC & NIVO & 10 & 0 & N.A. & 3.1 \\
\hline Garde-Noguera (2018) [34] & Retrospective & NSCLC & NIVO & 38 & 17.2 & 1.6 & 3.1 \\
\hline Gauvain (2018) [35] & Retrospective & NSCLC & NIVO & 30 & $9.0 *(95 \%$ CI $3.0-23.0)$ & $3.9+(95 \%$ CI $2.8-11.1)$ & N.R. \\
\hline Goldberg (2016) [36] & II & NSCLC & PEMBRO & 18 & $33.0 *(95 \%$ CI $14.0-59.0)$ & N.A. & 7.7 (95\% CI 3.5-N.R.) \\
\hline Spigel (2018) Cohort 3 [60] & II & NSCLC & ATEZO & 13 & $23.0(95 \%$ CI 5.0-54.0) & 2.5 & 6.8 (95\% CI 3.2-19.5) \\
\hline Flippot (2019) Cohort A [33] & II & RCC & NIVO & 39 & $11.8 *(95 \%$ CI $3.3-27.5)$ & $2.7+(95 \%$ CI $2.3-4.6)$ & N.A. \\
\hline Flippot (2019) Cohort B [33] & II & RCC & NIVO + Local Tx & 34 & N.A. & $4.8+(95 \%$ CI 3.0-8.0) & N.A. \\
\hline Sternberg (2019) [45] & III & UTC & ATEZO & 14 & $0(95 \%$ CI 0-23.0) & $2.0(95 \%$ CI $1.5-2.3)$ & 3.7 (95\% CI 1.5-7.0) \\
\hline
\end{tabular}

* Intracranial ORR; † Intracranial PFS. EAP Expanded access program; ICI Immune checkpoint inhibitor; IPI Ipilimumab; N.A. Not available; NIVO Nivolumab; N.R. Not reached; PEMBRO Pembrolizumab; UTC Urinary Tract Cancer. 


\subsection{Immune Checkpoint Inhibitors in Glioblastoma}

The efficacy and survival outcomes of all studies are summarized in Table 1 . The median survival of the patients with glioblastoma treated with ICI in all studies is 7.3 months. Furthermore, the median PFS reported in these studies was 2.1 months (Table 3).

Table 3. Median survival outcomes of immune checkpoint inhibitors in patients with glioblastoma or brain metastases.

\begin{tabular}{|c|c|c|c|c|c|c|c|c|c|}
\hline \multirow[t]{3}{*}{ Variable } & \multicolumn{4}{|c|}{ Glioblastoma } & \multicolumn{4}{|c|}{ Brain Metastases } & \multirow[b]{2}{*}{ All } \\
\hline & & \multicolumn{4}{|c|}{ Melanoma } & \multicolumn{3}{|c|}{ NSCLC } & \\
\hline & & IPI & NIVO & PEMBRO & IPI + NIVO & PEMBRO & NIVO & ATEZO & All \\
\hline $\begin{array}{c}\text { Median } \\
\text { Intracranial PFS }\end{array}$ & $2.1 \mathrm{mo}$ & $1.2-3.0 \mathrm{mo}$ & $2.3-2.5 \mathrm{mo}$ & N.A. & N.A. & N.A. & $3.9 \mathrm{mo}$ & N.A. & $2.7 \mathrm{mo}$ \\
\hline Median PFS & - & $3.0-3.1 \mathrm{mo}$ & N.A. & $2.0-5.2 \mathrm{mo}$ & $2.9 \mathrm{mo}$ & N.A. & $1.6-3.0 \mathrm{mo}$ & $2.5 \mathrm{mo}$ & $3.0 \mathrm{mo}$ \\
\hline Median OS & $7.3 \mathrm{mo}$ & $3.3-14.0 \mathrm{mo}$ & $5.1-18.5 \mathrm{mo}$ & $17.0-20.4 \mathrm{mo}$ & $17.4 \mathrm{mo}$ & $7.7 \mathrm{mo}$ & $2.8-9.0 \mathrm{mo}$ & $6.8 \mathrm{mo}$ & $8.0 \mathrm{mo}$ \\
\hline
\end{tabular}

ATEZO: Atezolizumab; PFS: Progression-free survival; OS: Overall survival; IPI: Ipilimumab; NIVO: Nivolumab; PEMBRO: Pembrolizumab. N.A.: Not available; mo: Months.

Overall, objective responses to ICI in recurrent glioblastoma were seen in three studies $[17,18,21]$. In the retrospective analysis of Carter et al., an ORR of 31\% was seen in patients with recurrent glioblastoma, who were treated with ipilimumab, $3 \mathrm{mg} / \mathrm{kg}$ Q3W, combined with bevacizumab [21]. In the phase I trial reported by Omuro et al., in 2018, objective responses were seen in two of the three treatment arms. The ORR in the treatment arms with nivolumab monotherapy $(3 \mathrm{mg} / \mathrm{kg}$ Q2W) and nivolumab (3 mg/kg Q2W) combined with ipilimumab $(1 \mathrm{mg} / \mathrm{kg})$ were $11 \%$ and $10 \%$, respectively [17]. Lastly, the phase I study of Lukas et al., with atezolizumab (1200 mg Q3W) in 16 patients with glioblastoma showed an ORR of $6.0 \%$ [18]. Three patients with IDH1-mutant tumors had better PFS (5.5 months vs. 1.2 months) and a trend towards a longer OS (16.0 months vs. 2.7 months) than patients with IDH1-wild-type tumors. Interestingly, neoadjuvant PD-1 blockade with pembrolizumab in patients with recurrent, surgically resectable glioblastoma demonstrated a significant improvement in OS compared to adjuvant PD-1 blockade alone. Furthermore, neoadjuvant PD-1 blockade was associated with upregulation of T cell and interferon- $\gamma$-related gene expression, but downregulation of genes related to the cell-cycle in the tumor [19]. Similar intratumoral and systemic immune changes were found in a single-arm, phase II trial with neoadjuvant nivolumab in surgically resectable, newly diagnosed or recurrent glioblastoma [20]. Currently, three important studies with nivolumab in newly-diagnosed and recurrent glioblastoma are awaiting final publication, but have reported preliminary, disappointing primary outcomes (Table 4). First, in the randomized, open-label, phase III CheckMate-143 trial (NCT02017717), nivolumab monotherapy did not significantly improve overall survival in patients with recurrent glioblastoma, compared to treatment with bevacizumab [65]. Furthermore, the combination of nivolumab with radiotherapy in the CheckMate-498 trial (NCT02617589) also failed to significantly prolong the overall survival of patients with newly diagnosed $\mathrm{O}^{6}$-methylguanine-DNA methyltransferase (MGMT)-unmethylated glioblastoma, compared to combined treatment with temozolomide and radiotherapy. Lastly, the addition of nivolumab to the first-line treatment with temozolomide and radiotherapy in newly diagnosed MGMT-methylated glioblastoma patients (CheckMate-548; NCT02667587), failed to meet one of its primary endpoints, i.e., PFS, and is currently awaiting the overall survival data.

\subsection{Outcomes of Immune Checkpoint Inhibitors in Brain Metastases}

An overview of the efficacy and survival outcomes is provided in Table 2 and Supplementary Table S2 for all studies with checkpoint inhibitors in brain metastases, and Table S3 for the studies that combined checkpoint inhibitors with radiotherapy. The median intracranial PFS for patients with brain metastases treated with ICI in these studies is 2.7 months, compared to an overall PFS of 3.0 months. The median survival of these patients reported in the studies was 8.0 months (Table 3 ). 
Table 4. Important studies with immune checkpoint inhibitors in newly-diagnosed and recurrent glioblastoma awaiting publication.

\begin{tabular}{ccccc}
\hline NCT Number & Official Trial Name & Phase & Primary Endpoint & Endpoint Status \\
\hline NCT02017717 & $\begin{array}{c}\text { A Study of the Effectiveness and Safety of Nivolumab Compared } \\
\text { to Bevacizumab and of Nivolumab With or Without Ipilimumab } \\
\text { in Glioblastoma Patients (CheckMate-143) }\end{array}$ & III & Overall survival & Endpoint not met \\
\hline NCT02617589 & $\begin{array}{c}\text { An Investigational Immuno-therapy Study of Nivolumab } \\
\text { Compared to Temozolomide, Each Given With Radiation Therapy, } \\
\text { for Newly-diagnosed Patients With Glioblastoma (GBM, a } \\
\text { Malignant Brain Cancer) (CheckMate-498) }\end{array}$ & III & Overall survival & Endpoint not met \\
\hline NCT02667587 & $\begin{array}{c}\text { An Investigational Immuno-therapy Study of Temozolomide Plus } \\
\text { Radiation Therapy With Nivolumab or Placebo, for Newly } \\
\text { Diagnosed Patients With Glioblastoma (GBM, a Malignant Brain } \\
\text { Cancer) (CheckMate-548) }\end{array}$ & III & $\begin{array}{c}\text { Progression-free survival } \\
\text { Overall survival }\end{array}$ & Endpoint not met \\
Endpoint in progress
\end{tabular}

In patients with melanoma BMs, 13 studies explored the efficacy of ipilimumab monotherapy. The pooled intracranial objective response rate (iORR) and ORR for ipilimumab are $9.0 \%\left(95 \%\right.$ CI $\left.3.0-17 ; \mathrm{I}^{2}=29 \%\right)$ and $14.0 \%\left(95 \%\right.$ CI $\left.6.0-24.0 \mathrm{I}^{2}=57 \%\right)$, respectively (Figure 2) $[25,26,28,30,31,39,41,44,46,48-50,55]$. Furthermore, the median survival in these studies ranged from 3.3 to 14.0 months and the intracranial PFS ranged from 1.2 to 3.0 months. For pembrolizumab monotherapy, four studies conducted in patients with melanoma BMs reported an intracranial ORR 22.0-40.0\% (Figure S1) [36-38,51]. The median PFS and OS of these patients were 2.0 to 5.2 months and 17.0-20.4 months, respectively. Long et al., and Larkin et al., explored the efficacy of nivolumab monotherapy in melanoma BMs [57]. The median survival and PFS for patients with BMs in these studies ranged from 5.1 to 18.5 months and 2.3 to 2.5 months, respectively. Furthermore, the reported intracranial ORR was $6.0-20.0 \%$. Lastly, three studies explored the efficacy of ipilimumab combined with nivolumab $[40,42,47]$. In two of the three studies, the median OS and PFS were not reached. However, Parakh et al., reported a median OS of 17.4 months (95\% CI 7.1-N.R.) and a PFS of 2.9 months (95\% CI 0.6-7.1) [42]. Interestingly, the intracranial ORR in these three studies were $18.0-55.0 \%$ (Figure S2).

A.

Study

Konstantinou (2014)

Margolin (2012) Cohort A

Margolin (2012) Cohort B

Random effects model

Heterogeneity: $I^{2}=29 \%, \tau^{2}=0.0029, p=0.25$
Events Total

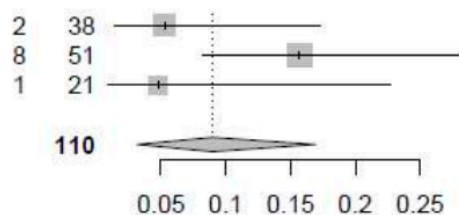

Proportion $\quad 95 \%-\mathrm{Cl}$ Weight

$0.05[0.01 ; 0.17] \quad 35.0 \%$

$0.16[0.08 ; 0.28] \quad 42.4 \%$

$0.05[0.01 ; 0.23] 22.6 \%$

$0.09[0.03 ; 0.17] 100.0 \%$

B.

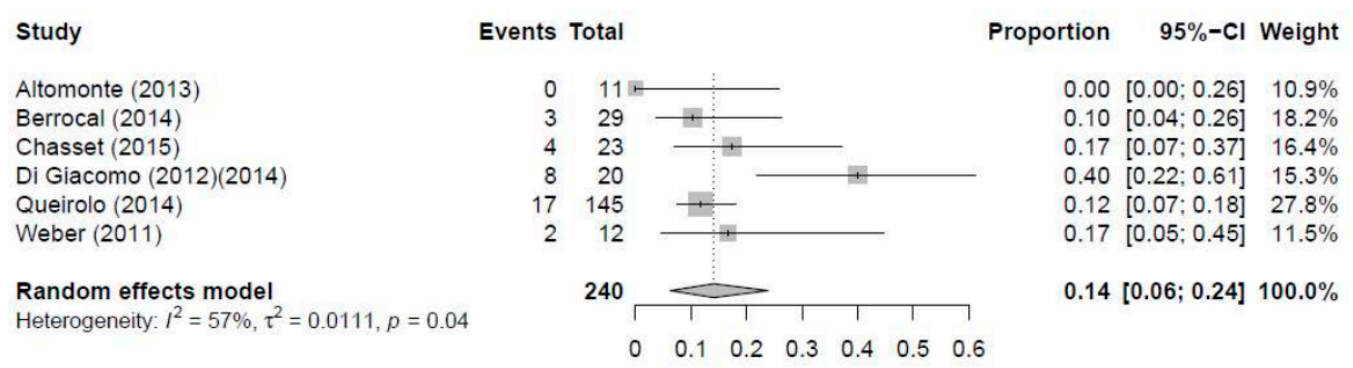

Figure 2. Pooled analysis for intracranial ORR (A) and overall ORR (B) of ipilimumab in patients with melanoma brain metastases.

In NSCLC brain metastases, eight studies reported efficacy and survival outcomes of treatment with ICI. In six studies with nivolumab monotherapy, the patients had a median survival of 3.1 to 9.0 months $[29,32,34,35,56,62]$. Furthermore, median PFS ranged from 1.6 to 3.0 months. The pooled 
ORR in these studies was 14\% (95\% CI 8.0-23.0; $\mathrm{I}^{2}=29 \%$ ) (Figure S3). Subsequently, Goldberg et al., reported an intracranial ORR of 33.0\% (95\% CI 14.0-59.0) in patients with NSCLC BMs treated with pembrolizumab [36]. The median survival of these patients was 7.7 months (95\% CI 3.5-N.R.). Lastly, Spigel et al., explored the efficacy of atezoluzimab in a cohort of patients with NSCLC and treated BMs [60]. The ORR in this cohort was $23.0 \%$ (95\% CI 5.0-54.0) and patients had a PFS and OS of 2.5 months and 6.8 months (95\% CI 3.2-19.5), respectively.

In other solid malignancies, only four studies reported efficacy and/or survival outcomes of patients with brain metastases, who were treated with ICI. First, in the phase II trial of Gadgeel et al., patients with small cell lung cancer (SCLC) were treated with pembrolizumab, $200 \mathrm{mg}$ Q3W [54]. The median survival of these patients was 9.6 months (95\% CI 7.0-12.0) and patients had a median PFS of 1.4 months (95\% CI 1.2-2.8). Second, Flippot et al., and De Giorgi et al., reported an intracranial ORR of $11.8 \%$ and an ORR of $18.8 \%$, respectively, in patients with renal cell cancer (RCC), who were treated with nivolumab, $3 \mathrm{mg} / \mathrm{kg}$ Q2W [33,52]. The median survival was not reached or available in these studies. However, Flippot et al., reported a median intracranial PFS 2.7 months (95\% CI 2.3-4.6), compared to 4.8 months ( $95 \%$ CI 3.0-8.0) for patients with RCC BMs, who were treated with nivolumab and local therapy. The median PFS of the patients in the study of De Giorgi et al., was 4.4 months $(95 \%$ CI 3.7-6.2). Lastly, the study of Sternberg et al., observed no objective responses in patients with BMs from urothelial and non-urothelial urinary tract carcinoma (UTC), treated with atezolizumab $1200 \mathrm{mg}$ Q3W [45]. The median PFS and OS of the patients in this study were 2.0 months (95\% CI 1.5-2.3) and 3.7 months (95\% CI 1.5-7.0), respectively.

\section{Discussion}

In this systematic review, we examined the efficacy and survival outcomes of checkpoint inhibitors in patients with glioblastoma and brain metastases.

For glioblastoma, we found that the vast majority of the studies with checkpoint inhibitors in recurrent glioblastoma showed minimal clinical activity. Furthermore, although currently awaiting final publication, preliminary results of the three landmark CheckMate studies with nivolumab have failed to meet their primary endpoint [65]. Based on these results, the use of immune checkpoint inhibitors is not applicable for patients with glioblastoma. Aside from the blood-brain barrier, which affects the drug delivery in brain tumors, it is suggested that several factors play an important role in the limited efficacy of checkpoint inhibitors in glioblastoma, compared to brain metastases of solid tumors. First, glioblastoma generally exhibits a relatively low mutational load compared to other solid tumors (i.e., melanoma and NSCLC), with an exemption of the infrequent cases of glioblastoma in which there is a defective mismatch repair system, resulting in a higher mutational load [66,67]. Furthermore, in contrast to melanoma and NSCLC brain metastases and their primary tumors, the gene expression signature of glioblastoma induces a highly immunosuppressive microenvironment, including a relatively low neoantigen burden and low number of tumor-infiltrating lymphocytes (TILs) [68,69]. Therefore, to overcome these difficulties, a multimodal, molecular approach may be necessary to increase the immune microenvironment and anti-tumor response in a selected subgroup of patients with glioblastoma.

Intracranial responses have been reported in studies with melanoma and NSCLC brain metastases. While multiple studies in melanoma brain metastases report intracranial objective responses with anti-PD-1 and/or anti-CTLA-4 immunotherapy, the evidence in NSCLSC BMs is limited to anti-PD-1 immunotherapy (i.e., predominantly nivolumab). Despite the encouraging evidence to presume that ICI can demonstrate intracranial objective responses in patients with brain metastases, the survival outcomes for these patients remain poor. Patients with brain metastases in the reviewed literature had a median intracranial and total PFS of 2.7 and 3.0 months, respectively. Furthermore, the reported median OS in all the reviewed studies was only 8.0 months. Several factors might play a role for the limited number of responses and poor PFS reported in patients with melanoma and NSCLC brain metastases. First, as with glioblastoma, the number of TILs in the microenvironment of brain metastases 
is highly heterogeneous and differs between patients [70]. Second, the density of these TILs seems to be significantly correlated with the amount of peritumoral brain edema and survival outcome in patients with brain metastases [71]. Lastly, it is hypothesized that the use of corticosteroids, which are frequently administered in patients with brain metastases and glioblastoma for the management of cerebral edema, may restrain a tumor-specific immune response to checkpoint inhibition by impairing T lymphocyte activation [41,72]. In particular, baseline use of steroids prior to the initiation of ICI seems to be correlated with a decreased ORR, PFS and OS, while the use of corticosteroid after initiation of ICI is not $[73,74]$.

Currently, only a small subset of patients with glioblastoma or BMs with microsatellite instable or mismatch repair deficient tumors, resulting in a higher tumor mutational burden, may benefit from ICI. Therefore, new treatment strategies are necessary to increase the response to ICI in patients with glioblastoma or BMs. First, the use of ICI in combination or in sequence with radiotherapy has mostly been explored in retrospective studies. Unfortunately, in the absence of randomized, prospective data, it is difficult to draw any conclusion about the optimal timing and sequencing of radiotherapy with ICI from these studies. Second, a potential way to overcome the highly immunosuppressive tumor microenvironment and low number of TILs is by inhibiting histone deacetylases (HDAC). Inhibition of HDACs lead to increased histone acetylation, resulting in increased gene expression [75]. Recently, both the HDAC inhibitor mocetinostat and inhibition of HDAC6 independently demonstrated a synergistic effect in combination with ICI, resulting in increased anti-tumor activity in NSCLC and ovarian cancer cell lines by increasing tumor antigen presentation and decreasing immune suppressive cell types [76,77]. Furthermore, in a phase I study, an adenovirus vector encoding the IL-12 gene was injected during surgery in the resection cavity walls of patients with recurrent high-grade glioma, followed by post-operative treatment with the oral activator for human IL-12, veledimex. In the tissue of five patients that received a re-resection, increased tumor-infiltrating lymphocytes producing interferon- $\gamma$ and PD-1 were seen, supporting the hypothesis of an immunological antitumor effect of human IL-12 [78]. Collectively, these data suggest that a multimodal approach is necessary to increase the activation of the immune system in the tumor microenvironment and anti-tumor response to ICI in patients with glioblastoma or BMs.

A few important limitations should be considered in the interpretation of the results reported in this systematic review. First, given the limited number of available randomized controlled trials and the retrospective nature of several included studies, the results in these studies are subjected to a certain degree of selection bias and therefore the real-world data may be worse. Subsequently, a considerable heterogeneity exists in the reported data of the studies, most likely due to the differences in study design, number of patients, study treatment and disease evaluation. A random effects models was used for our pooled analysis of ORR to minimize the bias in these data. Second, not every study included in this systematic review had complete data available for all the outcomes of interest. Furthermore, data on microsatellite stability, mismatch repair deficiency and tumor mutational burden were lacking. Therefore, unfortunately, no conclusions can be drawn about the correlation between the genetic profile and response to ICI. Lastly, most of the included studies predominantly focused on the use of ICI in melanoma BMs, compared to a select number of studies in NSCLC BMs and minimal data available in BMs of other solid tumors for which ICI are FDA-approved. Therefore, the outcomes of the studies with ICI in NSCLC BMs should be interpreted with caution and primarily in the setting of melanoma and NSCLC.

\section{Conclusions}

In conclusion, immune checkpoint inhibition, in its current state, demonstrates limited efficacy in glioblastoma and has failed to improve the survival of these patients. Therefore, for the future of immunotherapy in glioblastoma, research should focus on a multi-modal approach to activate local and systemic tumor-specific immune responses in glioblastoma. In patients with melanoma and NSCLC brain metastases, intracranial objective responses are seen with checkpoint inhibitors. 
However, due to the relatively poor overall survival, intracranial and total PFS with checkpoint inhibitors, local and systemic personalized treatment recommendations should be discussed in a multidisciplinary neuro-oncology tumor board. To move the field of checkpoint inhibition in brain metastases forward, we suggest more and larger prospective randomized controlled trials for patients with brain metastases. This must result in comprehensive evidence of the therapeutic potential of FDA-approved immune checkpoint inhibitors in brain metastases and subsequent determination of whether checkpoint inhibition improve quality of life and overall survival for these patients.

Supplementary Materials: The following are available online at http://www.mdpi.com/2072-6694/12/3/586/s1, Figure S1: Pooled analysis for intracranial ORR of pembrolizumab in patients with melanoma brain metastases, Figure S2. Pooled analysis for intracranial ORR of nivolumab combined with ipilimumab in patients with melanoma brain metastases, Figure S3. Pooled analysis for ORR of nivolumab in patients with NSCLC brain metastases, Table S1. Full overview of the complete search strategies, Table S2. Studies with immune checkpoint inhibitors in patients with brain metastases that only reported overall survival data, Table S3. Primary outcomes of clinical studies with immune checkpoint inhibitors and radiotherapy in patients with brain metastases, Table S4. Clinical studies with immune checkpoint inhibitors and radiotherapy in patients with brain metastases that only reported overall survival data.

Author Contributions: All authors were involved in the writing of the manuscript at draft and any revision stages, and have read and approved the final version. Conceptualization, C.G.B., M.E.v.L., H.M.W.V. and A.M.E.W.; Methodology, C.G.B., M.E.v.L., R.H.J.O. and M.W.H..; Formal Analysis, C.G.B., M.E.v.L. and M.W.H.; Resources, C.G.B., M.E.v.L. and R.H.J.O.; Data Collection, C.G.B., M.E.v.L. and R.H.J.O.; Writing-Original Draft Preparation, C.G.B., M.E.v.L., H.M.W.V. and A.M.E.W.; Writing-Review \& Editing, C.G.B., M.E.v.L., R.H.E., M.S., R.H.J.O., M.W.H., H.M.W.V. and A.M.E.W.; Supervision, H.M.W.V. and A.M.E.W. All authors have read and agreed to the published version of the manuscript.

Funding: This research received no external funding.

Conflicts of Interest: The authors declare no conflict of interest.

\section{References}

1. Omidi, Y.; Barar, J. Impacts of blood-brain barrier in drug delivery and targeting of brain tumors. BioImpacts BI 2012, 2, 5-22. [CrossRef]

2. Stupp, R.; Mason, W.P.; van den Bent, M.J.; Weller, M.; Fisher, B.; Taphoorn, M.J.; Belanger, K.; Brandes, A.A.; Marosi, C.; Bogdahn, U.; et al. Radiotherapy plus concomitant and adjuvant temozolomide for glioblastoma. N. Engl. J. Med. 2005, 352, 987-996. [CrossRef] [PubMed]

3. Stupp, R.; Hegi, M.E.; Mason, W.P.; van den Bent, M.J.; Taphoorn, M.J.; Janzer, R.C.; Ludwin, S.K.; Allgeier, A.; Fisher, B.; Belanger, K.; et al. Effects of radiotherapy with concomitant and adjuvant temozolomide versus radiotherapy alone on survival in glioblastoma in a randomised phase III study: 5-year analysis of the EORTC-NCIC trial. Lancet Oncol. 2009, 10, 459-466. [CrossRef]

4. Stupp, R.; Taillibert, S.; Kanner, A.; Read, W.; Steinberg, D.; Lhermitte, B.; Toms, S.; Idbaih, A.; Ahluwalia, M.S.; Fink, K.; et al. Effect of Tumor-Treating Fields Plus Maintenance Temozolomide vs Maintenance Temozolomide Alone on Survival in Patients with Glioblastoma: A Randomized Clinical Trial. Jama 2017, 318, 2306-2316. [CrossRef] [PubMed]

5. Almeida, J.P.; Chaichana, K.L.; Rincon-Torroella, J.; Quinones-Hinojosa, A. The value of extent of resection of glioblastomas: Clinical evidence and current approach. Curr. Neurol. Neurosci Rep. 2015, 15, 517. [CrossRef]

6. Romanelli, P.; Conti, A.; Pontoriero, A.; Ricciardi, G.K.; Tomasello, F.; De Renzis, C.; Innocenzi, G.; Esposito, V.; Cantore, G. Role of stereotactic radiosurgery and fractionated stereotactic radiotherapy for the treatment of recurrent glioblastoma multiforme. Neurosurg Focus 2009, 27, E8. [CrossRef]

7. De Witt Hamer, P.C. Small molecule kinase inhibitors in glioblastoma: A systematic review of clinical studies. Neuro. Oncol. 2010, 12, 304-316. [CrossRef]

8. Schouten, L.J.; Rutten, J.; Huveneers, H.A.; Twijnstra, A. Incidence of brain metastases in a cohort of patients with carcinoma of the breast, colon, kidney, and lung and melanoma. Cancer 2002, 94, 2698-2705. [CrossRef]

9. Barnholtz-Sloan, J.S.; Sloan, A.E.; Davis, F.G.; Vigneau, F.D.; Lai, P.; Sawaya, R.E. Incidence proportions of brain metastases in patients diagnosed (1973 to 2001) in the Metropolitan Detroit Cancer Surveillance System. J. Clin. Oncol. 2004, 22, 2865-2872. [CrossRef] 
10. Cagney, D.N.; Martin, A.M.; Catalano, P.J.; Redig, A.J.; Lin, N.U.; Lee, E.Q.; Wen, P.Y.; Dunn, I.F.; Bi, W.L.; Weiss, S.E.; et al. Incidence and prognosis of patients with brain metastases at diagnosis of systemic malignancy: A population-based study. Neuro. Oncol. 2017, 19, 1511-1521. [CrossRef]

11. Bafaloukos, D.; Gogas, H. The treatment of brain metastases in melanoma patients. Cancer Treat. Rev. 2004, 30, 515-520. [CrossRef] [PubMed]

12. Keir, M.E.; Butte, M.J.; Freeman, G.J.; Sharpe, A.H. PD-1 and its ligands in tolerance and immunity. Annu. Rev. Immunol. 2008, 26, 677-704. [CrossRef] [PubMed]

13. Bour-Jordan, H.; Esensten, J.H.; Martinez-Llordella, M.; Penaranda, C.; Stumpf, M.; Bluestone, J.A. Intrinsic and extrinsic control of peripheral T-cell tolerance by costimulatory molecules of the CD28/ B7 family. Immunol. Rev. 2011, 241, 180-205. [CrossRef] [PubMed]

14. Hodi, F.S.; O’Day, S.J.; McDermott, D.F.; Weber, R.W.; Sosman, J.A.; Haanen, J.B.; Gonzalez, R.; Robert, C.; Schadendorf, D.; Hassel, J.C.; et al. Improved survival with ipilimumab in patients with metastatic melanoma. N. Engl. J. Med. 2010, 363, 711-723. [CrossRef]

15. Herbst, R.S.; Baas, P.; Kim, D.W.; Felip, E.; Perez-Gracia, J.L.; Han, J.Y.; Molina, J.; Kim, J.H.; Arvis, C.D.; Ahn, M.J.; et al. Pembrolizumab versus docetaxel for previously treated, PD-L1-positive, advanced non-small-cell lung cancer (KEYNOTE-010): A randomised controlled trial. Lancet 2016, 387, 1540-1550. [CrossRef]

16. Brahmer, J.R.; Tykodi, S.S.; Chow, L.Q.; Hwu, W.J.; Topalian, S.L.; Hwu, P.; Drake, C.G.; Camacho, L.H.; Kauh, J.; Odunsi, K.; et al. Safety and activity of anti-PD-L1 antibody in patients with advanced cancer. $N$. Engl. J. Med. 2012, 366, 2455-2465. [CrossRef]

17. Omuro, A.; Vlahovic, G.; Lim, M.; Sahebjam, S.; Baehring, J.; Cloughesy, T.F.; Voloschin, A.; Ramkissoon, S.H.; Ligon, K.L.; Latek, R.; et al. Nivolumab with or without ipilimumab in patients with recurrent glioblastoma: Results from exploratory phase i cohorts of CheckMate 143. Neuro-Oncol. 2018, 20, 674-686. [CrossRef]

18. Lukas, R.V.; Rodon, J.; Becker, K.; Wong, E.T.; Shih, K.; Touat, M.; Fasso, M.; Osborne, S.; Molinero, L.; O'Hear, C.; et al. Clinical activity and safety of atezolizumab in patients with recurrent glioblastoma. J. Neurooncol. 2018, 140,317-328. [CrossRef]

19. Cloughesy, T.F.; Mochizuki, A.Y.; Orpilla, J.R.; Hugo, W.; Lee, A.H.; Davidson, T.B.; Wang, A.C.; Ellingson, B.M.; Rytlewski, J.A.; Sanders, C.M.; et al. Neoadjuvant anti-PD-1 immunotherapy promotes a survival benefit with intratumoral and systemic immune responses in recurrent glioblastoma. Nat. Med. 2019, 25, 477-486. [CrossRef]

20. Schalper, K.A.; Rodriguez-Ruiz, M.E.; Diez-Valle, R.; Lopez-Janeiro, A.; Porciuncula, A.; Idoate, M.A.; Inoges, S.; de Andrea, C.; Lopez-Diaz de Cerio, A.; Tejada, S.; et al. Neoadjuvant nivolumab modifies the tumor immune microenvironment in resectable glioblastoma. Nat. Med. 2019, 25, 470-476. [CrossRef]

21. Carter, T.; Shaw, H.; Cohn-Brown, D.; Chester, K.; Mulholland, P. Ipilimumab and Bevacizumab in Glioblastoma. Clin. Oncol. (R Coll Radiol) 2016, 28, 622-626. [CrossRef] [PubMed]

22. Blumenthal, D.T.; Yalon, M.; Vainer, G.W.; Lossos, A.; Yust, S.; Tzach, L.; Cagnano, E.; Limon, D.; Bokstein, F. Pembrolizumab: First experience with recurrent primary central nervous system (CNS) tumors. J. Neurooncol. 2016, 129, 453-460. [CrossRef] [PubMed]

23. Chamberlain, M.C.; Kim, B.T. Nivolumab for patients with recurrent glioblastoma progressing on bevacizumab: A retrospective case series. J. Neurooncol. 2017, 133, 561-569. [CrossRef] [PubMed]

24. Mantica, M.; Pritchard, A.; Lieberman, F.; Drappatz, J. Retrospective study of nivolumab for patients with recurrent high grade gliomas. J. Neurooncol. 2018, 139, 625-631. [CrossRef]

25. Altomonte, M.; Di Giacomo, A.M.; Queirolo, P.; Ascierto, P.A.; Spagnolo, F.; Bajetta, E.; Calabrò, L.; Danielli, R.; De Rosa, F.; Maur, M.; et al. Clinical experience with ipilimumab $10 \mathrm{mg} / \mathrm{kg}$ in patients with melanoma treated at Italian centres as part of a European expanded access programme. J. Exp. Clin. Cancer Res. 2013, 32, 82. [CrossRef]

26. Berrocal, A.; Arance, A.; Martin, J.A.L.; Soriano, V.; Muñoz, E.; Alonso, L.; Espinosa, E.; Criado, P.L.; Valdivia, J.; Algarra, S.M. Ipilimumab for advanced melanoma: Experience from the Spanish Expanded Access Program. Melanoma Res. 2014, 24, 577-583. [CrossRef]

27. Bjørnhart, B.; Hansen, K.H.; Jørgensen, T.L.; Herrstedt, J.; Schytte, T. Efficacy and safety of immune checkpoint inhibitors in a Danish real life non-small cell lung cancer population: A retrospective cohort study. Acta Oncologica. 2019, 58, 953-961. [CrossRef] 
28. Chasset, F.; Pages, C.; Biard, L.; Roux, J.; Sidina, I.; Madelaine, I.; Basset-Seguin, N.; Viguier, M.; Madjlessi-Ezr, A.N.; Schneider, P.; et al. Single-center study under a French Temporary Authorization for Use (TAU) protocol for ipilimumab in metastatic melanoma: Negative impact of baseline corticosteroids. Eur. J. Dermatol. 2015, 25, 36-44. [CrossRef]

29. Crino, L.; Bronte, G.; Bidoli, P.; Cravero, P.; Minenza, E.; Cortesi, E.; Garassino, M.C.; Proto, C.; Cappuzzo, F.; Grossi, F.; et al. Nivolumab and brain metastases in patients with advanced non-squamous non-small cell lung cancer. Lung Cancer 2019, 129, 35-40. [CrossRef]

30. Di Giacomo, A.M.; Ascierto, P.A.; Pilla, L.; Santinami, M.; Ferrucci, P.F.; Giannarelli, D.; Marasco, A.; Rivoltini, L.; Simeone, E.; Nicoletti, S.V.; et al. Ipilimumab and fotemustine in patients with advanced melanoma (NIBIT-M1): An open-label, single-arm phase 2 trial. Lancet Oncol. 2012, 13, 879-886. [CrossRef]

31. Di Giacomo, A.M.; Ascierto, P.A.; Queirolo, P.; Pilla, L.; Ridolfi, R.; Santinami, M.; Testori, A.; Simeone, E.; Guidoboni, M.; Maurichi, A.; et al. Three-year follow-up of advanced melanoma patients who received ipilimumab plus fotemustine in the Italian Network for Tumor Biotherapy (NIBIT)-M1 phase II study. Ann. Oncol. 2015, 26, 798-803. [CrossRef] [PubMed]

32. Dumenil, C.; Massiani, M.A.; Dumoulin, J.; Giraud, V.; Labrune, S.; Chinet, T.; Giroux Leprieur, E. Clinical factors associated with early progression and grade 3-4 toxicity in patients with advanced non-small-cell lung cancers treated with nivolumab. PLoS ONE 2018, 13, e0195945. [CrossRef]

33. Flippot, R.; Dalban, C.; Laguerre, B.; Borchiellini, D.; Gravis, G.; Negrier, S.; Chevreau, C.; Joly, F.; Geoffrois, L.; Ladoire, S.; et al. Safety and Efficacy of Nivolumab in Brain Metastases from Renal Cell Carcinoma: Results of the GETUG-AFU 26 NIVOREN Multicenter Phase II Study. J. Clin. Oncol. 2019, 37, 2008-2016. [CrossRef] [PubMed]

34. Garde-Noguera, J.; Martorell, P.M.; De Julian, M.; Altozano, J.P.; Coloma, C.S.; Sanchez, J.G.; Molla, A.I.; Martin, M.; Rubio, X.M.; Liebana, S.M.; et al. Predictive and prognostic clinical and pathological factors of nivolumab efficacy in non-small-cell lung cancer patients. Clin. Transl. Oncol. 2018, 20, 1072-1079. [CrossRef] [PubMed]

35. Gauvain, C.; Vauléon, E.; Chouaid, C.; Lerhun, E.; Jabot, L.; Scherpereel, A.; Vinas, F.; Cortot, A.B.; Monnet, I. Intracerebral efficacy and tolerance of nivolumab in non-small-cell lung cancer patients with brain metastases. Lung Cancer 2018, 116, 62-66. [CrossRef] [PubMed]

36. Goldberg, S.B.; Gettinger, S.N.; Mahajan, A.; Chiang, A.C.; Herbst, R.S.; Sznol, M.; Tsiouris, A.J.; Cohen, J.; Vortmeyer, A.; Jilaveanu, L.; et al. Pembrolizumab for patients with melanoma or non-small-cell lung cancer and untreated brain metastases: Early analysis of a non-randomised, open-label, phase 2 trial. Lancet Oncol. 2016, 17, 976-983. [CrossRef]

37. Gonzalez-Cao, M.; Arance, A.; Piulats, J.M.; Marquez-Rodas, I.; Manzano, J.L.; Berrocal, A.; Crespo, G.; Rodriguez, D.; Perez-Ruiz, E.; Berciano, M.; et al. Pembrolizumab for advanced melanoma: Experience from the Spanish Expanded Access Program. Clin. Transl. Oncol. 2017, 19, 761-768. [CrossRef]

38. Kluger, H.M.; Chiang, V.; Mahajan, A.; Zito, C.R.; Sznol, M.; Tran, T.; Weiss, S.A.; Cohen, J.V.; Yu, J.; Hegde, U.; et al. Long-Term Survival of Patients with Melanoma with Active Brain Metastases Treated With Pembrolizumab on a Phase II Trial. J. Clin. Oncol. 2019, 37, 52-60. [CrossRef]

39. Konstantinou, M.P.; Dutriaux, C.; Gaudy-Marqueste, C.; Mortier, L.; Bedane, C.; Girard, C.; Thellier, S.; Jouary, T.; Grob, J.J.; Richard, M.A.; et al. Ipilimumab in melanoma patients with brain metastasis: A retro-spective multicentre evaluation of thirty-eight patients. Acta Derm. Venereol. 2014, 94, 45-49. [CrossRef]

40. Long, G.V.; Atkinson, V.; Lo, S.; Sandhu, S.; Guminski, A.D.; Brown, M.P.; Wilmott, J.S.; Edwards, J.; Gonzalez, M.; Scolyer, R.A.; et al. Combination nivolumab and ipilimumab or nivolumab alone in melanoma brain metastases: A multicentre randomised phase 2 study. Lancet Oncol. 2018, 19, 672-681. [CrossRef]

41. Margolin, K.; Ernstoff, M.S.; Hamid, O.; Lawrence, D.; McDermott, D.; Puzanov, I.; Wolchok, J.D.; Clark, J.I.; Sznol, M.; Logan, T.F.; et al. Ipilimumab in patients with melanoma and brain metastases: An open-label, phase 2 trial. Lancet Oncol. 2012, 13, 459-465. [CrossRef]

42. Parakh, S.; Randhawa, M.; Nguyen, B.; Warburton, L.; Hussain, M.A.; Cebon, J.; Millward, M.; Yip, D.; Ali, S. Real-world efficacy and toxicity of combined nivolumab and ipilimumab in patients with metastatic melanoma. Asia Pac. J. Clin. Oncol 2019, 15, 26-30. [CrossRef] [PubMed]

43. Parakh, S.; Park, J.J.; Mendis, S.; Rai, R.; Xu, W.; Lo, S.; Drummond, M.; Rowe, C.; Wong, A.; McArthur, G.; et al. Efficacy of anti-PD-1 therapy in patients with melanoma brain metastases. Br. J. Cancer 2017, 116, 1558-1563. [CrossRef] [PubMed] 
44. Queirolo, P.; Spagnolo, F.; Ascierto, P.A.; Simeone, E.; Marchetti, P.; Scoppola, A.; Del Vecchio, M.; Di Guardo, L.; Maio, M.; Di Giacomo, A.M.; et al. Efficacy and safety of ipilimumab in patients with advanced melanoma and brain metastases. J. Neurooncol. 2014, 118, 109-116. [CrossRef]

45. Sternberg, C.N.; Loriot, Y.; James, N.; Choy, E.; Castellano, D.; Lopez-Rios, F.; Banna, G.L.; De Giorgi, U.; Masini, C.; Bamias, A.; et al. Primary Results from SAUL, a Multinational Single-arm Safety Study of Atezolizumab Therapy for Locally Advanced or Metastatic Urothelial or Nonurothelial Carcinoma of the Urinary Tract. Eur. Urol. 2019, 76, 73-81. [CrossRef]

46. Weber, J.S.; Amin, A.; Minor, D.; Siegel, J.; Berman, D.; O’Day, S.J. Safety and clinical activity of ipilimumab in melanoma patients with brain metastases: Retrospective analysis of data from a phase 2 trial. Melanoma Res. 2011, 21, 530-534. [CrossRef]

47. Tawbi, H.A.; Forsyth, P.A.; Algazi, A.; Hamid, O.; Hodi, F.S.; Moschos, S.J.; Khushalani, N.I.; Lewis, K.; Lao, C.D.; Postow, M.A.; et al. Combined Nivolumab and Ipilimumab in Melanoma Metastatic to the Brain. N. Engl. J. Med. 2018, 379, 722-730. [CrossRef]

48. Alexander, M.; Mellor, J.D.; McArthur, G.; Kee, D. Ipilimumab in pretreated patients with unresectable or metastatic cutaneous, uveal and mucosal melanoma. Med. J. Aust. 2014, 201, 49-53. [CrossRef]

49. Ahmad, S.S.; Qian, W.; Ellis, S.; Mason, E.; Khattak, M.A.; Gupta, A.; Shaw, H.; Quinton, A.; Kovarikova, J.; Thillai, K.; et al. Ipilimumab in the real world: The UK expanded access programme experience in previously treated advanced melanoma patients. Melanoma Res. 2015, 25, 432-442. [CrossRef]

50. Ascierto, P.A.; Del Vecchio, M.; Robert, C.; Mackiewicz, A.; Chiarion-Sileni, V.; Arance, A.; Lebbe, C.; Bastholt, L.; Hamid, O.; Rutkowski, P.; et al. Ipilimumab $10 \mathrm{mg} / \mathrm{kg}$ versus ipilimumab $3 \mathrm{mg} / \mathrm{kg}$ in patients with unresectable or metastatic melanoma: A randomised, double-blind, multicentre, phase 3 trial. Lancet Oncol. 2017, 18, 611-622. [CrossRef]

51. Dagogo-Jack, I.; Lanfranchi, M.; Gainor, J.F.; Giobbie-Hurder, A.; Lawrence, D.P.; Shaw, A.T.; Sullivan, R.J. A Retrospective Analysis of the Efficacy of Pembrolizumab in Melanoma Patients with Brain Metastasis. J. Immunother. 2017, 40, 108-113. [CrossRef] [PubMed]

52. De Giorgi, U.; Carteni, G.; Giannarelli, D.; Basso, U.; Galli, L.; Cortesi, E.; Caserta, C.; Pignata, S.; Sabbatini, R.; Bearz, A.; et al. Safety and efficacy of nivolumab for metastatic renal cell carcinoma: Real-world results from an expanded access programme. BJU Int. 2019, 123, 98-105. [CrossRef] [PubMed]

53. Forschner, A.; Eichner, F.; Amaral, T.; Keim, U.; Garbe, C.; Eigentler, T.K. Improvement of overall survival in stage IV melanoma patients during 2011-2014: Analysis of real-world data in 441 patients of the German Central Malignant Melanoma Registry (CMMR). J. Cancer Res. Clin. Oncol. 2017, 143, 533-540. [CrossRef] [PubMed]

54. Gadgeel, S.M.; Pennell, N.A.; Fidler, M.J.; Halmos, B.; Bonomi, P.; Stevenson, J.; Schneider, B.; Sukari, A.; Ventimiglia, J.; Chen, W.; et al. Phase II Study of Maintenance Pembrolizumab in Patients with Extensive-Stage Small Cell Lung Cancer (SCLC). J. Thorac. Oncol. 2018, 13, 1393-1399. [CrossRef]

55. Jinga, D.C.; Ciuleanu, T.; Negru, S.; Aldea, C.; Gales, L.; Bacanu, F.; Oprean, C.; Manolache, M.; Zob, D.; Curescu, S.; et al. Effectiveness and safety profile of ipilimumab therapy in previously treated patients with unresectable or metastatic melanoma-The Romanian Patient Access Program. JBUON 2018, 22, 1287-1295.

56. Juergens, R.A.; Mariano, C.; Jolivet, J.; Finn, N.; Rothenstein, J.; Reaume, M.N.; Faghih, A.; Labbe, C.; Owen, S.; Shepherd, F.A.; et al. Real-world benefit of nivolumab in a Canadian non-small-cell lung cancer cohort. Curr. Oncol. 2018, 25, 384-392. [CrossRef]

57. Larkin, J.; Minor, D.; D’Angelo, S.; Neyns, B.; Smylie, M.; Miller, W.H., Jr.; Gutzmer, R.; Linette, G.; Chmielowski, B.; Lao, C.D.; et al. Overall Survival in Patients with Advanced Melanoma Who Received Nivolumab Versus Investigator's Choice Chemotherapy in CheckMate 037: A Randomized, Controlled, Open-Label Phase III Trial. J. Clin. Oncol. 2018, 36, 383-390. [CrossRef]

58. Mangana, J.; Cheng, P.F.; Kaufmann, C.; Amann, V.C.; Frauchiger, A.L.; Stogner, V.; Held, U.; von Moos, R.; Michielin, O.; Braun, R.P.; et al. Multicenter, real-life experience with checkpoint inhibitors and targeted therapy agents in advanced melanoma patients in Switzerland. Melanoma Res. 2017, 27, 358-368. [CrossRef]

59. Milsch, L.; Gesierich, A.; Kreft, S.; Livingstone, E.; Zimmer, L.; Goebeler, M.; Schadendorf, D.; Schilling, B. Patterns of disease control and survival in patients with melanoma brain metastases undergoing immune-checkpoint blockade. Eur. J. Cancer 2018, 99, 58-65. [CrossRef] 
60. Spigel, D.R.; Chaft, J.E.; Gettinger, S.; Chao, B.H.; Dirix, L.; Schmid, P.; Chow, L.Q.M.; Hicks, R.J.; Leon, L.; Fredrickson, J.; et al. FIR: Efficacy, Safety, and Biomarker Analysis of a Phase II Open-Label Study of Atezolizumab in PD-L1-Selected Patients with NSCLC. J. Thorac. Oncol. 2018, 13, 1733-1742. [CrossRef]

61. Schvartsman, G.; Ma, J.; Bassett, R.L., Jr.; Haydu, L.E.; Amaria, R.N.; Hwu, P.; Wong, M.K.; Hwu, W.J.; Diab, A.; Patel, S.P.; et al. Incidence, patterns of progression, and outcomes of preexisting and newly discovered brain metastases during treatment with anti-PD-1 in patients with metastatic melanoma. Cancer 2019, 125, 4193-4202. [CrossRef]

62. Tamiya, M.; Tamiya, A.; Inoue, T.; Kimura, M.; Kunimasa, K.; Nakahama, K.; Taniguchi, Y.; Shiroyama, T.; Isa, S.I.; Nishino, K.; et al. Metastatic site as a predictor of nivolumab efficacy in patients with advanced non-small cell lung cancer: A retrospective multicenter trial. PLoS ONE 2018, 13, e0192227. [CrossRef] [PubMed]

63. Vosoughi, E.; Lee, J.M.; Miller, J.R.; Nosrati, M.; Minor, D.R.; Abendroth, R.; Lee, J.W.; Andrews, B.T.; Leng, L.Z.; Wu, M.; et al. Survival and clinical outcomes of patients with melanoma brain metastasis in the era of checkpoint inhibitors and targeted therapies. BMC Cancer 2018, 18, 490. [CrossRef] [PubMed]

64. Liu, F.X.; Ou, W.; Diede, S.J.; Whitman, E.D. Real-world experience with pembrolizumab in patients with advanced melanoma: A large retrospective observational study. Medicine (Baltimore) 2019, 98, e16542. [CrossRef] [PubMed]

65. Reardon, D.; Omuro, A.; Brandes, A.; Rieger, J.; Wick, A.; Sepulveda, J.; Phuphanich, S.; De Souza, P.; Ahluwalia, M.; Lim, M. OS10. 3 randomized phase 3 study evaluating the efficacy and safety of nivolumab vs bevacizumab in patients with recurrent glioblastoma: CheckMate 143. Neuro-oncology 2017, 19 , iii21. [CrossRef]

66. Colli, L.M.; Machiela, M.J.; Myers, T.A.; Jessop, L.; Yu, K.; Chanock, S.J. Burden of Nonsynonymous Mutations among TCGA Cancers and Candidate Immune Checkpoint Inhibitor Responses. Cancer Res. 2016, 76, 3767-3772. [CrossRef]

67. Hodges, T.R.; Ott, M.; Xiu, J.; Gatalica, Z.; Swensen, J.; Zhou, S.; Huse, J.T.; de Groot, J.; Li, S.; Overwijk, W.W.; et al. Mutational burden, immune checkpoint expression, and mismatch repair in glioma: Implications for immune checkpoint immunotherapy. Neuro. Oncol. 2017, 19, 1047-1057. [CrossRef]

68. Schumacher, T.N.; Schreiber, R.D. Neoantigens in cancer immunotherapy. Science 2015, 348, 69-74. [CrossRef]

69. Lim, M.; Xia, Y.; Bettegowda, C.; Weller, M. Current state of immunotherapy for glioblastoma. Nat. reviews. Clin. Oncol. 2018, 15, 422-442. [CrossRef]

70. Berghoff, A.S.; Lassmann, H.; Preusser, M.; Hoftberger, R. Characterization of the inflammatory response to solid cancer metastases in the human brain. Clin. Exp. Metastasis 2013, 30, 69-81. [CrossRef]

71. Berghoff, A.S.; Fuchs, E.; Ricken, G.; Mlecnik, B.; Bindea, G.; Spanberger, T.; Hackl, M.; Widhalm, G.; Dieckmann, K.; Prayer, D.; et al. Density of tumor-infiltrating lymphocytes correlates with extent of brain edema and overall survival time in patients with brain metastases. Oncoimmunology 2016, 5, e1057388. [CrossRef] [PubMed]

72. Reardon, D.A.; Neuberg, D.S.; Keskin, D.B.; Tirosh, I.; Anandappa, A.; Mathewson, N.D.; Sun, J.; Shukla, S.A.; Gjini, E.; Li, S. Effect of dexamethasone in glioblastoma (GBM) patients on systemic and intratumoral T-cell responses induced by personalized neoantigen-targeting vaccine. J. Clin. Oncol. 2018, 36, 2020. [CrossRef]

73. Arbour, K.C.; Mezquita, L.; Long, N.; Rizvi, H.; Auclin, E.; Ni, A.; Martinez-Bernal, G.; Ferrara, R.; Lai, W.V.; Hendriks, L.E.L.; et al. Impact of Baseline Steroids on Efficacy of Programmed Cell Death-1 and Programmed Death-Ligand 1 Blockade in Patients with Non-Small-Cell Lung Cancer. J. Clin. Oncol. 2018, 36, 2872-2878. [CrossRef] [PubMed]

74. Horvat, T.Z.; Adel, N.G.; Dang, T.O.; Momtaz, P.; Postow, M.A.; Callahan, M.K.; Carvajal, R.D.; Dickson, M.A.; D’Angelo, S.P.; Woo, K.M.; et al. Immune-Related Adverse Events, Need for Systemic Immunosuppression, and Effects on Survival and Time to Treatment Failure in Patients With Melanoma Treated with Ipilimumab at Memorial Sloan Kettering Cancer Center. J. Clin. Oncol. 2015, 33, 3193-3198. [CrossRef] [PubMed]

75. Zagni, C.; Floresta, G.; Monciino, G.; Rescifina, A. The Search for Potent, Small-Molecule HDACIs in Cancer Treatment: A Decade After Vorinostat. Med. Res. Rev. 2017, 37, 1373-1428. [CrossRef] [PubMed]

76. Briere, D.; Sudhakar, N.; Woods, D.M.; Hallin, J.; Engstrom, L.D.; Aranda, R.; Chiang, H.; Sodre, A.L.; Olson, P.; Weber, J.S.; et al. The class I/IV HDAC inhibitor mocetinostat increases tumor antigen presentation, decreases immune suppressive cell types and augments checkpoint inhibitor therapy. Cancer Immunol. Immunother. CII 2018, 67, 381-392. [CrossRef] 
77. Fukumoto, T.; Fatkhutdinov, N.; Zundell, J.A.; Tcyganov, E.N.; Nacarelli, T.; Karakashev, S.; Wu, S.; Liu, Q.; Gabrilovich, D.I.; Zhang, R. HDAC6 Inhibition Synergizes with Anti-PD-L1 Therapy in ARID1A-Inactivated Ovarian Cancer. Cancer Res. 2019, 79, 5482-5489. [CrossRef]

78. Chiocca, E.A.; Yu, J.S.; Lukas, R.V.; Solomon, I.H.; Ligon, K.L.; Nakashima, H.; Triggs, D.A.; Reardon, D.A.; Wen, P.; Stopa, B.M.; et al. Regulatable interleukin-12 gene therapy in patients with recurrent high-grade glioma: Results of a phase 1 trial. Sci. Transl. Med. 2019, 11, eaaw5680. [CrossRef]

(C) 2020 by the authors. Licensee MDPI, Basel, Switzerland. This article is an open access article distributed under the terms and conditions of the Creative Commons Attribution (CC BY) license (http://creativecommons.org/licenses/by/4.0/). 